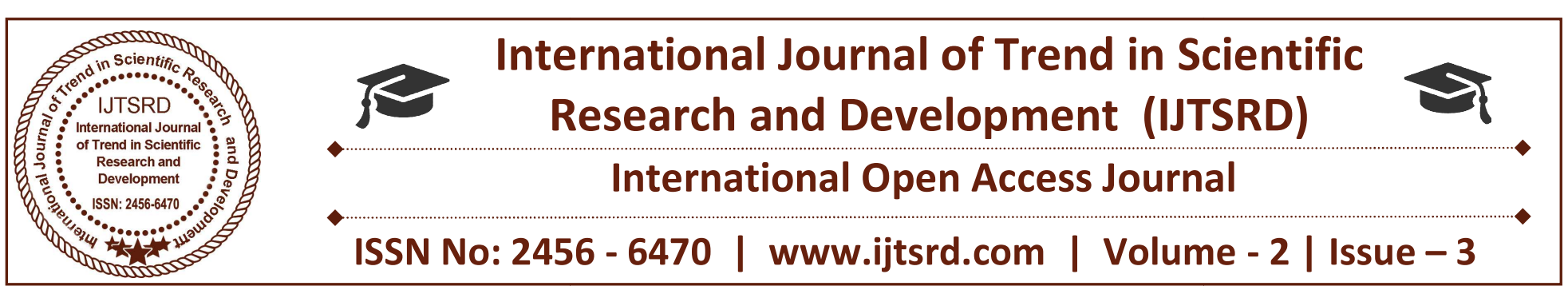

\title{
Study on utilization of fly Ash in Bitumen and in Flexible Pavements
}

\author{
Abdula Zain Ul Aabideen Dar \\ Student, Al-Falah University, \\ Faridabad, Haryana, India
}

\author{
Mohd Zeeshan Khan \\ Assistant Professor, Al-Falah University, \\ Faridabad, Haryana, India
}

\section{ABSTRACT}

Asphalt also known as bitumen, is a sticky, black and highly viscous liquid or semi-solid that is present in most crude petroleum's and in some natural deposits, it is a substance classed as a pitch. The primary use of asphalt is in road construction, where it is used as the glue or binder mixed with aggregate particles to create asphalt concrete. Its other main uses are for bituminous waterproofing products, including production of roofing felt and for sealing flat roofs. The terms asphalt and bitumen are often used interchangeably to mean both natural and manufactured forms of the substance. In American English, asphalt (or asphalt cement) is the carefully refined residue from the distillation process of selected crude oils.

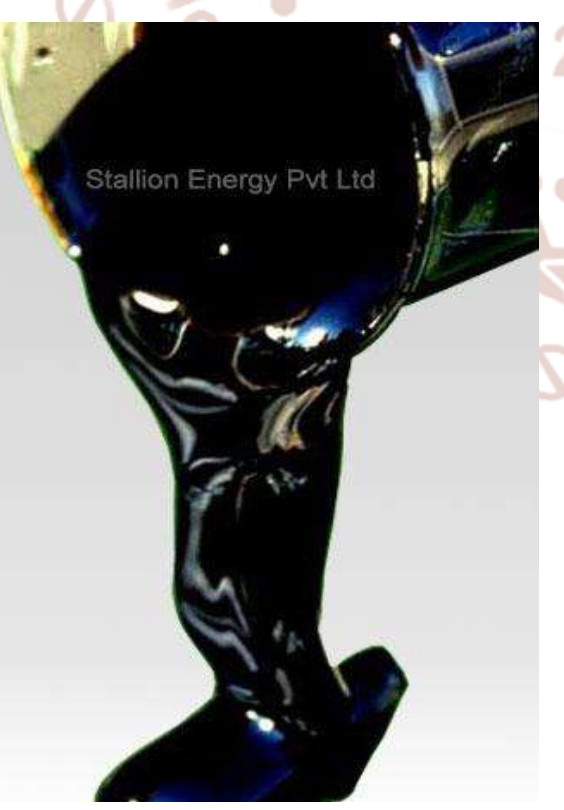

Fig 1.1: Sample Picture of Bitumen/Asphalt.
Fly ash is one of the residues formed in combustion and consists of the fine particles that rise with the flue gases. It is a waste material and is dumped on the land. In India, 95 million tons of fly ash is generated every year which has occupied approximately 65,000 acres of land. Coal requirement and generation of fly ash estimated for the year 2031-2032 is around 1,800 million tons and 600 million tons respectively (MOST-2010). From the above figures, it is clear that there is huge amount of unused fly ash which has to be disposed of each year. Highway industry is capable of using waste material in large quantities if their effect on pavement performance proves to be technically, economically and environmentally satisfactory. Fly ash has successfully been used as filler for bitumen mixes for a long time and has the advantage of increasing the resistance of bitumen mixes to moisture damage. In addition to filling voids, fly ash was reported to have the ability to work as a bitumen extender. Fly ash was used as filler material replaced by stone dust at different percentage $(0 \%$, $50 \%$ and $100 \%$ ) and prepared Marshall Sample with different percentage of binder. Fly ash has pozzolanic properties and can therefore be stabilized to achieve higher strength and durability required for use as pavement substructure specifically as sub-base or base layer material. The stabilization of fly ash can be achieved by adding either cement, lime or other materials. Stabilization of fly ash with available industrial by-products is also possible and is gaining researchers' attention now a day. Considerable economic as well as environmental benefits can be achieved when bulk amount of fly ash is utilized along with other potential waste materials. 
With the changing life style among different classes of the society, road network has become one of the essential backbones for the movement from place to place as it provides a good access for the commuters to travel to their desired place. Road network has been adopted long ago by the people when other modes of transport were not even invented. Road transportation is the mode that has expanded the most over the last 50 years, both for passengers and freight transportation.

In road network majority of the roads constructed consists of flexible pavement. Flexible pavement generally comprises of four layers:

(I) Soil sub grade

(II) Sub base course

(III) Base course

(IV) Surface course

\section{Objectives of the study}

The primary objectives of the present study are:

To evaluate the properties of bitumen having different percentages of fly ash as admixture.

$>$ To compare the performance of modified bitumen with fly ash as an admixture with that of the virgin bitumen through laboratory investigation.

\section{Scope of the study}

To meet the above objectives, the scope of the project will be formulated as follows:

Properties of modified and unmodified bitumen

\begin{tabular}{|c|c|c|c|c|}
\hline \multirow{2}{*}{ Test } & \multicolumn{3}{|c|}{ Modified Bitumen } & Unmodified \\
\cline { 2 - 4 } & $\mathbf{4 \%}$ Fly ash & 6\% Fly ash & $\mathbf{8 \% ~ F l y ~ a s h ~}$ & Bitumen \\
\hline Penetration Test & $45.2 \mathrm{~mm}$ & $38.5 \mathrm{~mm}$ & $31.6 \mathrm{~mm}$ & $63.5 \mathrm{~mm}$ \\
\hline Ductility & $48 \mathrm{~cm}$ & $40.5 \mathrm{~cm}$ & $37.8 \mathrm{~cm}$ & $100+$ \\
\hline Specific Gravity & 1.08 & 1.09 & 1.1 & 1.04 \\
\hline
\end{tabular}

\section{Observations evaluated from Marshall Test}

Determination of data obtained from Marshall Test using virgin Bitumen:

Marshall Characteristics of a mix using virgin bitumen

\begin{tabular}{|c|c|c|c|c|c|}
\hline $\begin{array}{c}\text { Bitumen } \\
\text { content }(\%)\end{array}$ & $\begin{array}{c}\text { Unit density } \\
(\mathrm{Gm})\end{array}$ & $\begin{array}{c}\text { Air Void } \\
(\%)(\mathrm{Vv})\end{array}$ & $\begin{array}{c}\text { VFB } \\
(\%)\end{array}$ & $\begin{array}{c}\text { Stability } \\
(\mathrm{Kg})\end{array}$ & $\begin{array}{c}\text { Flow } \\
(\mathrm{mm})\end{array}$ \\
\hline 4.5 & 2.292 & 4.8 & 79.66 & 27.88 & 6 \\
\hline 5 & 2.297 & 4.0 & 82.37 & 44.2 & 8.6 \\
\hline 5.5 & 2.89 & 3.7 & 83.40 & 39.44 & 10.8 \\
\hline
\end{tabular}


International Journal of Trend in Scientific Research and Development (IJTSRD) ISSN: 2456-6470

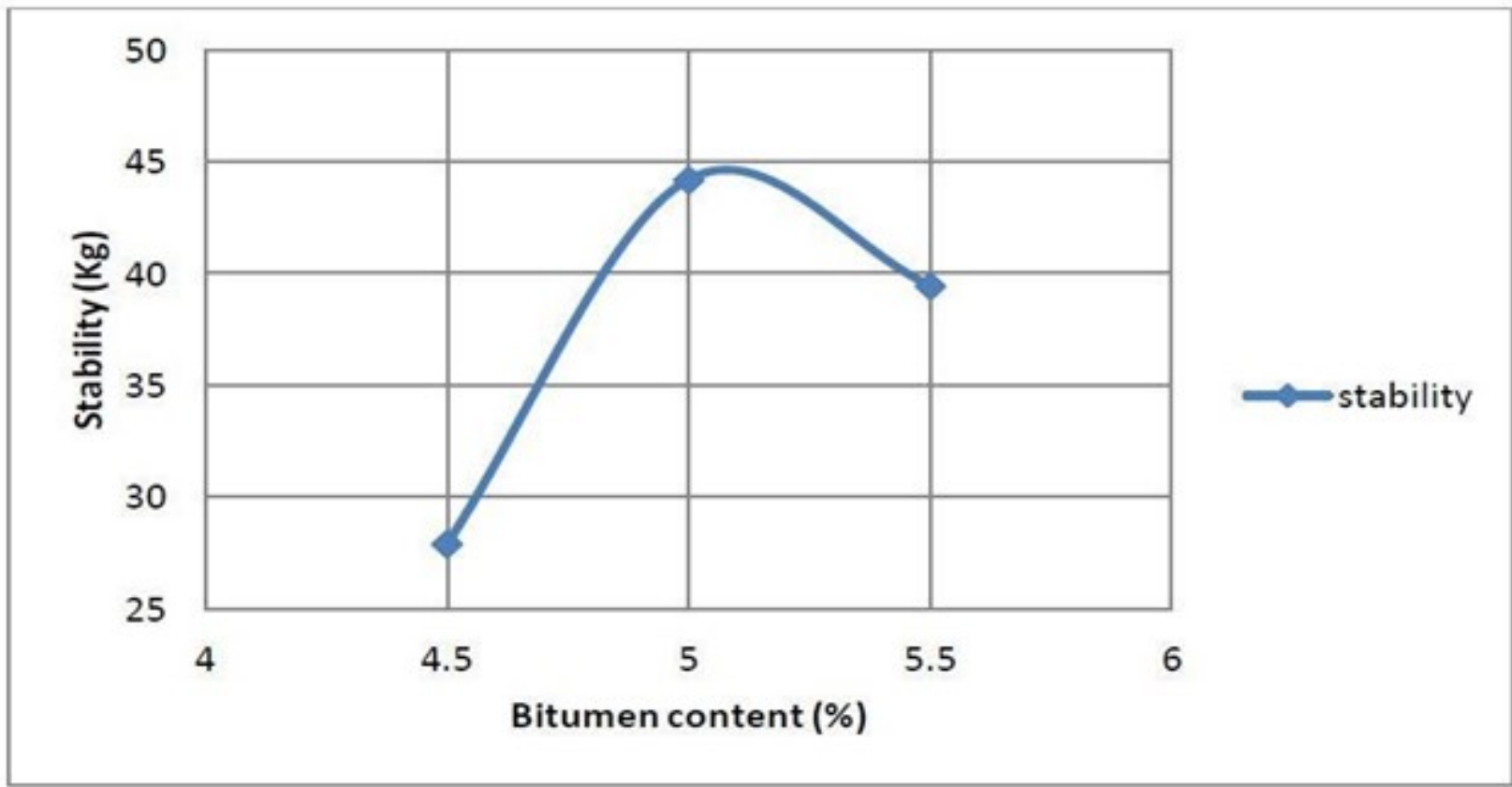

Marshall Stability value

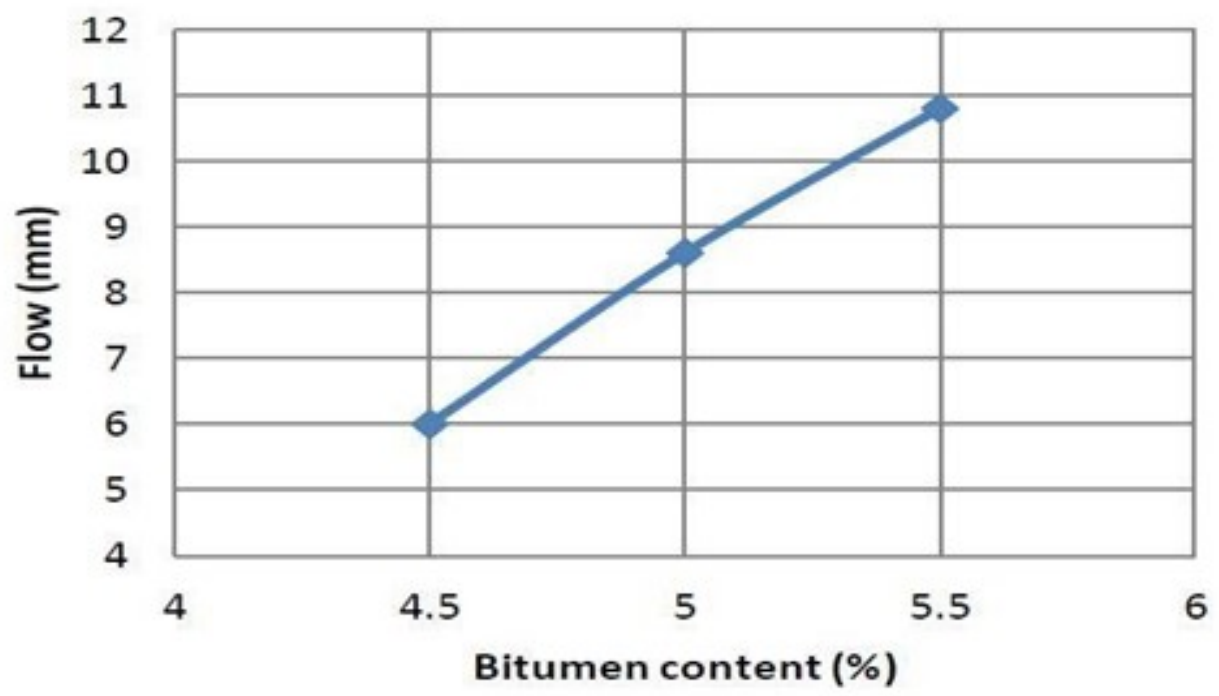

Marshall Flow value

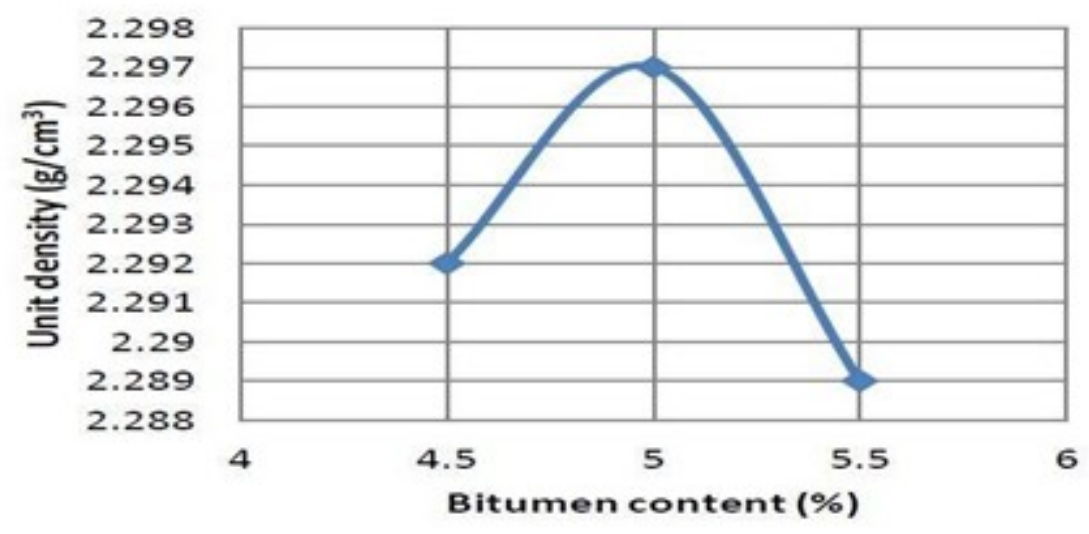

Unit density of bituminous mix 
International Journal of Trend in Scientific Research and Development (IJTSRD) ISSN: 2456-6470

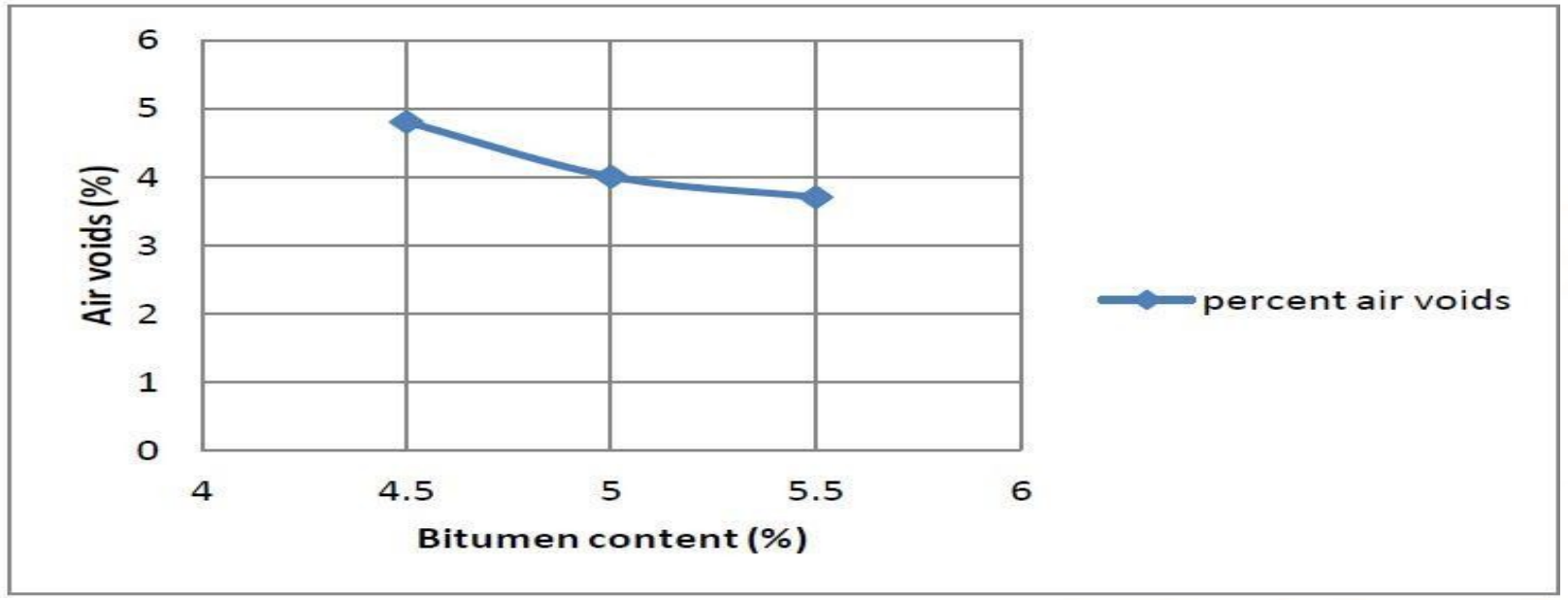

Percentage Air voids in bituminous mix

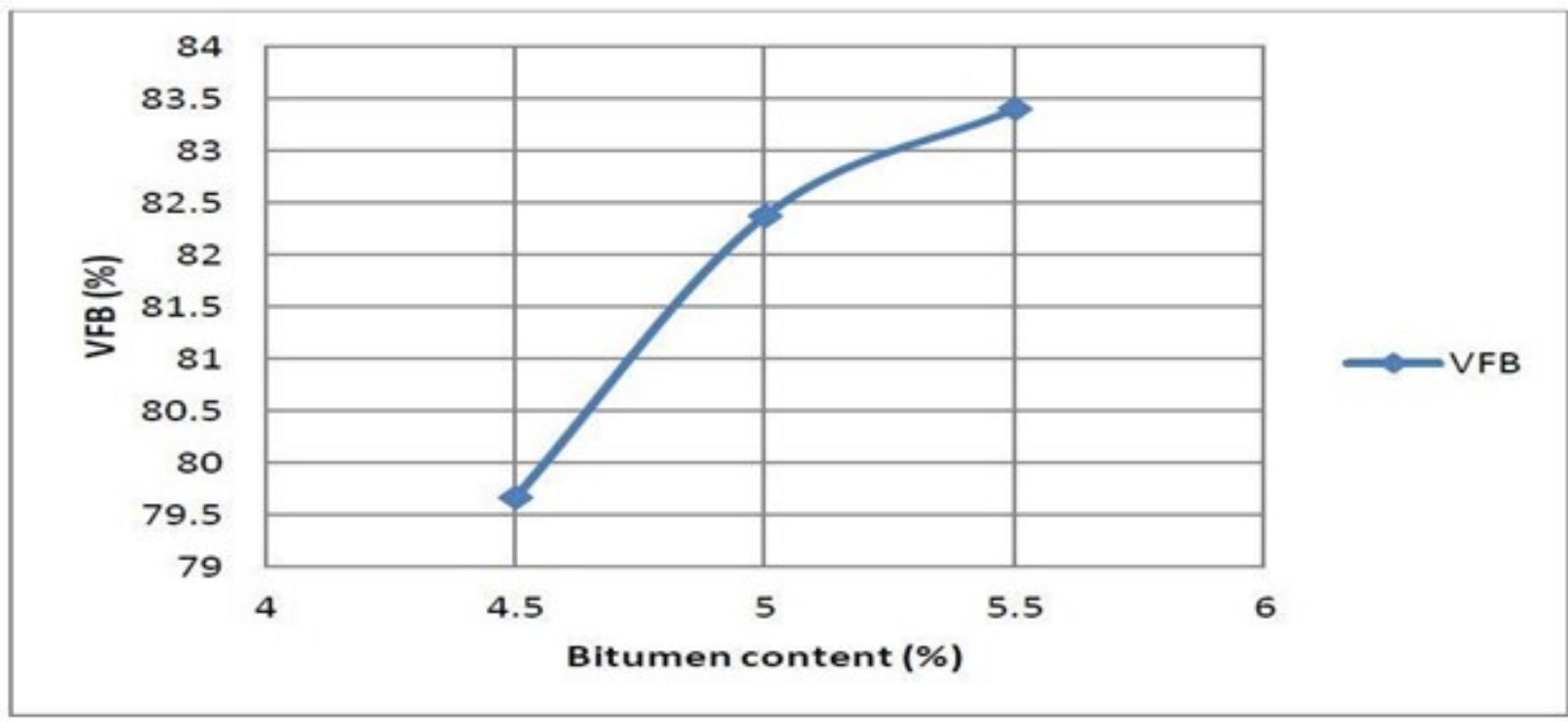

Percent Voids filled with bitumen in mix

The optimum bitumen content value for stability calculated came out to at $5.1 \%$ bitumen.

Marshall Characteristics of a mix using modified bitumen

\begin{tabular}{|l|l|l|l|l|l|l|}
\hline $\begin{array}{l}\text { Bitumen } \\
\text { content (\%) }\end{array}$ & $\begin{array}{l}\text { Fly Ash } \\
\text { Content (\%) }\end{array}$ & $\begin{array}{l}\text { Unit density } \\
(\mathrm{Gm})\end{array}$ & $\begin{array}{l}\text { Air Void } \\
(\%)(\mathrm{Vv})\end{array}$ & $\begin{array}{l}\text { VFB } \\
(\%)\end{array}$ & $\begin{array}{l}\text { Stability } \\
(\mathrm{Kg})\end{array}$ & $\begin{array}{l}\text { Flow } \\
(\mathrm{mm})\end{array}$ \\
\hline 4.5 & 4 & 2.31 & 11.8 & 58.74 & 55.9 & 6 \\
\hline 4.5 & 6 & 2.286 & 12.9 & 55.972 & 69.3 & 6.6 \\
\hline 4.5 & 8 & 2.267 & 13.5 & 55 & 76.1 & 7.8 \\
\hline 5 & 4 & 2.41 & 7.7 & 68.95 & 60.52 & 4.4 \\
\hline 5 & 6 & 2.40 & 8.0 & 68.25 & 70.72 & 5.4 \\
\hline 5 & 8 & 2.36 & 9.2 & 64.48 & 74.8 & 6.1 \\
\hline 5.5 & 4 & 2.35 & 9.3 & 65.05 & 70.72 & 3.25 \\
\hline 5.5 & 6 & 2.33 & 9.7 & 63.26 & 75.82 & 4.2 \\
\hline 5.5 & 8 & 2.295 & 11.3 & 58.91 & 78.20 & 6.1 \\
\hline
\end{tabular}




\section{CONCLUSIONS AND FUTURE SCOPE}

\section{Conclusions}

Based on the results of the experimental investigations conducted on normal and modified bitumen using fly ash in different quantities to modify virgin bitumen, the following summaries have been drawn:

- Modified bitumen by using different percentage of fly ash shows less penetration value thus low grade bitumen can be modified to withstand higher loads.

- The ductility values decreased with increase in percentage of fly ash as the fly ash caused the bitumen to become stiffer.

- From Marshall Stability test, the stability values were found to be increased as the fly ash content increased. Fly ash tends to fill more voids between aggregate grains. Thus mix will continue to gain strength thus leading to increase in stability of the bituminous mix.
- The Marshall Flow value increases with increase in the percentage of fly ash in binder. This indicates improvements in the resistance to permanent deformation of bituminous mixes with addition of fly ash.

- The density of bituminous mixes prepared with using modified binder decrease as the fly ash content in bitumen increase.

\section{Future scope}

- Evaluation of Indirect tensile strength of mixes prepared from modified binder using fly ash.

- Evaluation of fatigue performance of bituminous mixes prepared with modified bitumen by using different percentage of fly ash.

- Find out the relative rutting characteristics of different bituminous mixes by using Static Indentation Test at $60 \mathrm{oC}$. 